\title{
Detecting hydrological landscapes over the Bay of Biscay continental shelf in spring
}

\author{
${\text { Benjamin Planque }{ }^{1, *}, \text { Pascal Lazure }}^{2}$, Anne-Marie Jégou ${ }^{2}$ \\ ${ }^{1}$ Institut Français de Recherche pour l'Exploitation de la Mer (IFREMER), Département Ecologie et Modèles \\ pour l'Halieutique, rue de l'île d'Yeu, BP 21105, 44311 Nantes Cedex 3, France
}

${ }^{2}$ Institut Français de Recherche pour l'Exploitation de la Mer (IFREMER), DEL/AO, BP 70, 29280 Plouzané, France

\begin{abstract}
A complex set of hydrodynamical structures co-exist over the Bay of Biscay continental shelf. These structures, which can spread over a limited spatial range $(10 \mathrm{~s}$ of $\mathrm{km})$ and last for periods ranging from days to months, influence the rates and nature of biological production. They need to be accurately described before the mechanisms linking hydrodynamics to production can be unraveled. Such description generally requires not only 3D observations of hydrological fields (temperature, salinity, density), but also a description of how these fields vary with time. This is hardly achievable with current means of field observation but can be mimicked by hydrodynamic model simulations. Using simulations from a 3D hydrodynamic model, we developed a methodology that allows for the description of hydrological landscapes, i.e. a description of the 3D fields and of their changes with time. The method was applied to the structures present over the Bay of Biscay shelf in spring. Eight hydrological landscapes were identified: high estuary, low estuary, coastal, river plume, near coastal, central shelf, open shelf and northwestern shelf. With this technique, we show that structures that have been qualitatively described in the literature can be identified objectively and that some new structures can be detected. All 8 hydrological landscapes are found every year, but their spatial extent can vary greatly from year to year. This variation for all landscapes except for the northwestern shelf can be summarised by a single index, which is strongly related to the runoff from the main rivers along the French coast.
\end{abstract}

KEY WORDS: Bay of Biscay $\cdot$ Hydrology $\cdot$ Hydrodynamic model $\cdot$ Spring $\cdot$ Typology

\section{INTRODUCTION}

Climatic and hydrological variations in the ocean are known to control a large fraction of the spatial and temporal variability in marine populations, from primary production to top predators. Over large scales, changes in ocean circulation patterns are known to alter the geographical distribution of plankton (e.g. Beaugrand et al. 2002) and fish (e.g. Lehodey et al. 1997). At a regional scale, a number of processes such as upwellings, tidal fronts, eddies, jet currents, or river discharge are also known to modulate the regimes of production and distribution of marine species (e.g. Mann \& Lazier 1991, Bakun 1996). These features of the marine environment are partly responsible, through complex webs, for year to year fluctuations in abundance and spatial distribution of marine fish populations.

In this study, we address the problem of describing features of the marine environment (i.e. hydrodynamics), during the spring season, over the Bay of Biscay continental shelf (off the French coast). As in other coastal areas, different hydrodynamic structures can co-exist in the Bay of Biscay. However, the particular configuration of the Bay of Biscay is responsible for a high variability in such structures, which can display a limited spatial range $(10 \mathrm{~s}$ of $\mathrm{km})$ and last for periods ranging from days to months. The Bay of Biscay is at an eastern boundary, which unlike western boundaries, is not subjected to intense oceanic currents. The tidal characteristics which result from tidal propagation over changing bathymetry results in regional scale 
variations in mixing/stratification and internal waves. In addition, freshwater runoff in the Bay of Biscay is high, with an average above $70 \mathrm{~km}^{3} \mathrm{yr}^{-1}$ (about $1 \mathrm{~km}^{3}$ per $1000 \mathrm{~km}^{2}$ of shelf, more than twice the value for the North Sea). Finally, the mid latitudinal location of the Bay of Biscay makes it prone to variable winds and storms. The resulting combination of multiple and sometimes short-lived structures makes a description and understanding of its coastal hydrodynamics difficult. This difficulty is often increased by the fact that an accurate description of these structures requires not only 3D observations of hydrological fields (temperature, salinity, density, velocity), but also a description of how these fields vary with time. Such descriptions can hardly be obtained from field data because repeated synoptic 3D observations over large shelf areas are not compatible with the observational methods available on hydrographic research cruises. Alternatively, it is possible to extract such information from realistic numerical 3D model simulations which mimic the high-frequency hydrodynamical changes taking place at regional scales over shelf areas.

However, even when simulations from 3D hydrodynamic models are available, one difficulty persists. It is that of summarising the hydrodynamical outputs (a succession of 3D hydrological fields) and reduce them to a limited number of features that can make sense to the marine ecologist.

The objective of this study is to introduce a method which summarises the temporal evolution of hydrological conditions in the form of a limited number of 'hydrological landscapes'. We present an application of this method to hydrodynamic model simulations over the Bay of Biscay continental shelf in spring during 1987 to 2001.

\section{MATERIALS AND METHODS}

2.1. 3D hydrodynamic model. The $3 \mathrm{D}$ hydrodynamic model covers the continental shelf on a $5 \times 5 \mathrm{~km}$ grid, with 10 vertical layers in sigma coordinates (i.e. layer thicknesses are proportional to bottom depth). The model is forced by realistic wind and river runoff conditions. Free surface boundary conditions are produced by a larger model; temperature at the open boundary is interpolated and salinity is relaxed toward 35.6 when currents enter the domain. The simulation outputs (temperature, salinity, and density 3D fields) are for the period 1987 to 2001, and each year data are extracted between 1 March and 30 June. A more comprehensive description of model characteristics is given in Appendix 1.

2.2. Simplification and summary of hydrological vertical profiles. The data table resulting from the hydrodynamic model simulation consist of 2845 grid points for which temperature (T), salinity (S) and density (D) profiles are available (3 parameters, 10 layers) for 59 dates each year and for $15 \mathrm{yr}$. The data table contains $2845 \times 3 \times 10 \times 59 \times 15=75.5 \times 10^{6}$ values. The size and complexity of this database renders any data analysis complex and time and resource consuming. To reduce the size of the database, an attempt was made to simplify the information contained in each hydrological vertical profile by retaining only a few key parameters. The criteria for retaining the parameters are described in detail in Planque et al. (in press). These criteria are as follows: (1) the modelled parameters can also be observed in the field; (2) they are relevant to hydrology and biology; (3) they are less variable in time than in space; and (4) the number of parameters retained should be small.

Criterion 3 is particularly important with regard to the construction of regional hydrological entities during the spring season, when temporal variations in hydrological structures can easily exceed geographical differences (this is the case for sea surface temperature which rapidly increases during spring, and was therefore not retained). The selection process resulted in the identification of the following 4 parameters: surface salinity (SS), bottom temperature (BT), mixed-layer depth (MLD) and potential energy deficit (PED: a measure of the amount of energy needed to vertically re-homogenise the water column) (Fig. 1). SS is primarily related to the extent of river outflow over the shelf, whilst BT reflects a

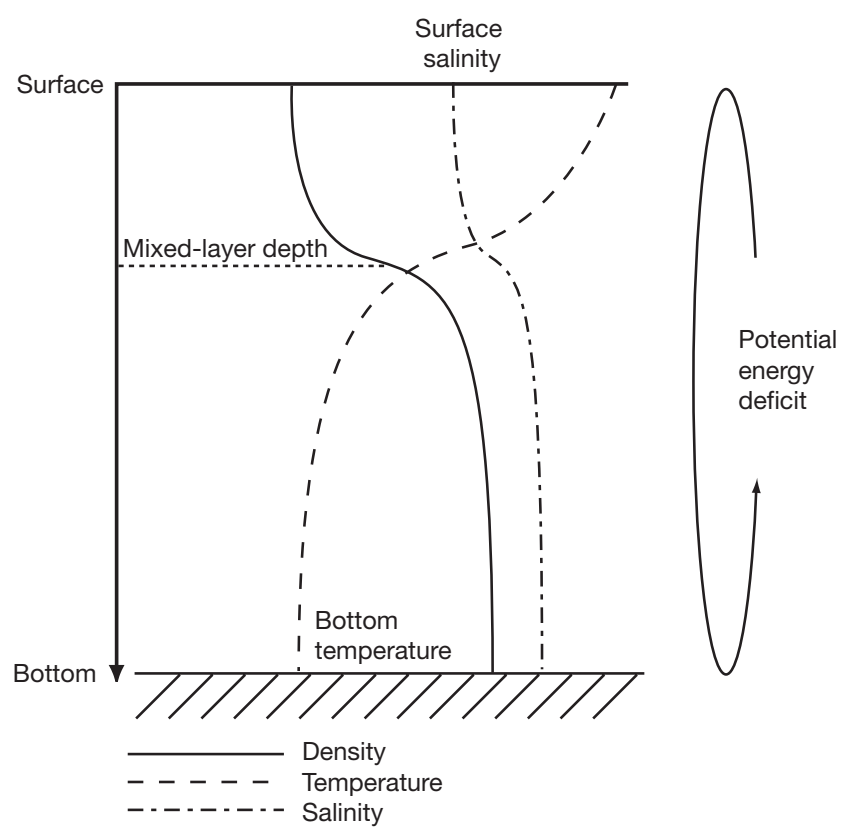

Fig. 1. A vertical hydrological profile on the continental shelf in spring, showing temperature, salinity, and density against depth of measurement. The 4 parameters retained to characterise the profile are surface salinity, bottom temperature, mixed-layer depth, and potential energy deficit 
combination of the previous winter situation and heat penetration through the water column. The stratification is described by the combination of the MLD, which provides an indication of stratification vertical extent, and of the PED, which indicates stratification intensity.

SS and BT were directly extracted from the model output, whilst MLD and PRD were calculated from the vertical density profiles, as in Planque et al. (in press). This first step results in a simplification of the data table and a reduction to $10 \times 10^{6}$ values. An additional advantage of the data transformation is that it becomes possible to easily represent graphically the geographical distribution of these 4 parameters, which is not feasible with combined T, S and D vertical profiles.

2.3. Transformation and simplification of temporal changes in hydrology. The spring dynamics of hydrology at each location can be described by the timeseries of SS, BT, MLD and PED in the data table. The parameters have different units and different ranges of values. To ensure they were given equal weight in the subsequent analysis, each parameter was standardised to zero mean and unit variance. The series of standardised parameters form the basis of the typology described in the following section.

At this stage the data table is still very large and difficult to handle in common statistical packages. Furthermore, it is likely that the dynamics of each year/ location which is described by 4 time series of 59 values can be summarised with a reduced number of descriptors. The summary is achieved by performing a principal component analysis (PCA) on the data table. Only the first 13 axes of PCA were retained, as they accounted for over $90 \%$ of the variance of the data table. This second step resulted in a simplification of the data table and a reduction to $0.5 \times 10^{6}$ values.

The 2 steps of data preparation have resulted in a 140 -fold reduction in the data table size. The resulting data table configuration allows for clustering analysis.

2.4. Typology of spring hydrodynamics. For different types of spring hydrodynamics to be defined, it is necessary to define a measure of similarity (or dissimilarity) between hydrodynamics. In this case, 2 dynamics were considered similar if their associated timeseries for SS, BT, MLD and PED were similar. In this way, it was possible to compare the spring hydrological dynamics at a specific location in a given year with the dynamics at any other location and/or any other year. The measure of dissimilarity was made by calculating Euclidean distance between series.

$$
D(i, j)=\sqrt{\sum_{t} \sum_{p}\left[x_{i}(t, p)-x_{j}(t, p)\right]^{2}}
$$

where $D(i, j)$ is the distance (or dissimilarity) between the hydrological dynamics at location/year $i$ and the hydrological dynamics at location/year $j$, and $x(t, p)$ is the standardised value of parameter $p$ (SS, BT, MLD or PED) at time $t$ (Days 1 to 59).

The data table used was the simplified table taken from the PCA, and distance was calculated as follows:

$$
D(i, j)=\sqrt{\sum_{n}\left[x_{i}(n)-x_{j}(n)\right]^{2}}
$$

where $x(n)$ is the value of the $n$th PCA component for a given location/year. When all PCA components are used, Eqs. (1) \& (2) are equivalent. In the present case only 13 (out of 236) PCA axes were kept. The resulting slight differences between the 2 equations were considered negligible.

The typology (i.e. the construction of hydrological types or landscapes) can be performed by agglomerative techniques, i.e. grouping successively elements with high similarities, or by partitioning methods, i.e. splitting the entire dataset into a number of subgroups showing little similarity between them. Agglomerative techniques require calculation of the distance $D(i, j)$ between all possible pairs of observations. This is hardly computable in the present case (as it would require the calculation of $900 \times 10^{6}$ distances). The $K$ means partitioning method was chosen instead as it allows for partitioning directly from the data table, without the need to compute the full distance matrix beforehand. More details on $K$-means partitioning can be found in Jain \& Dubes (1988) and Legendre \& Legendre (1998). The algorithm was run using the Statistical toolbox 4.0 in Matlab 6.5. Each resulting partition can be characterised by a 'centroid', i.e. the mean hydrodynamical characteristics of all year/locations belonging to the same partition (or landscape).

One sensitive issue in clustering or partitioning is the definition of the optimal number of groups to be retained. We used an objective measure of partitioning efficiency, the Davies-Bouldin index. This index is a measure of the ratio of similarities among objects of the same groups and dissimilarities between objects of different groups (Davies-Bouldin 1979).

2.5. Annual stability of group characteristics. The output from the above partitioning method is a limited number of hydrological landscapes which result from the analysis of all years of data pooled together. It is, however, conceivable that these 'average' landscapes may not adequately represent individual years if unusual hydrodynamical situations occur. To assess the degree of interannual variability in hydrodynamical landscapes, we compared centroids calculated from the entire dataset (as above) with centroids calculated from data of single years. The 2 types of centroids were combined in a multi-dimensional scaling analysis (MDS) (Kruskal 1964), so that the cohesion (or dispersion) of individual years around the average centroids can be displayed. 

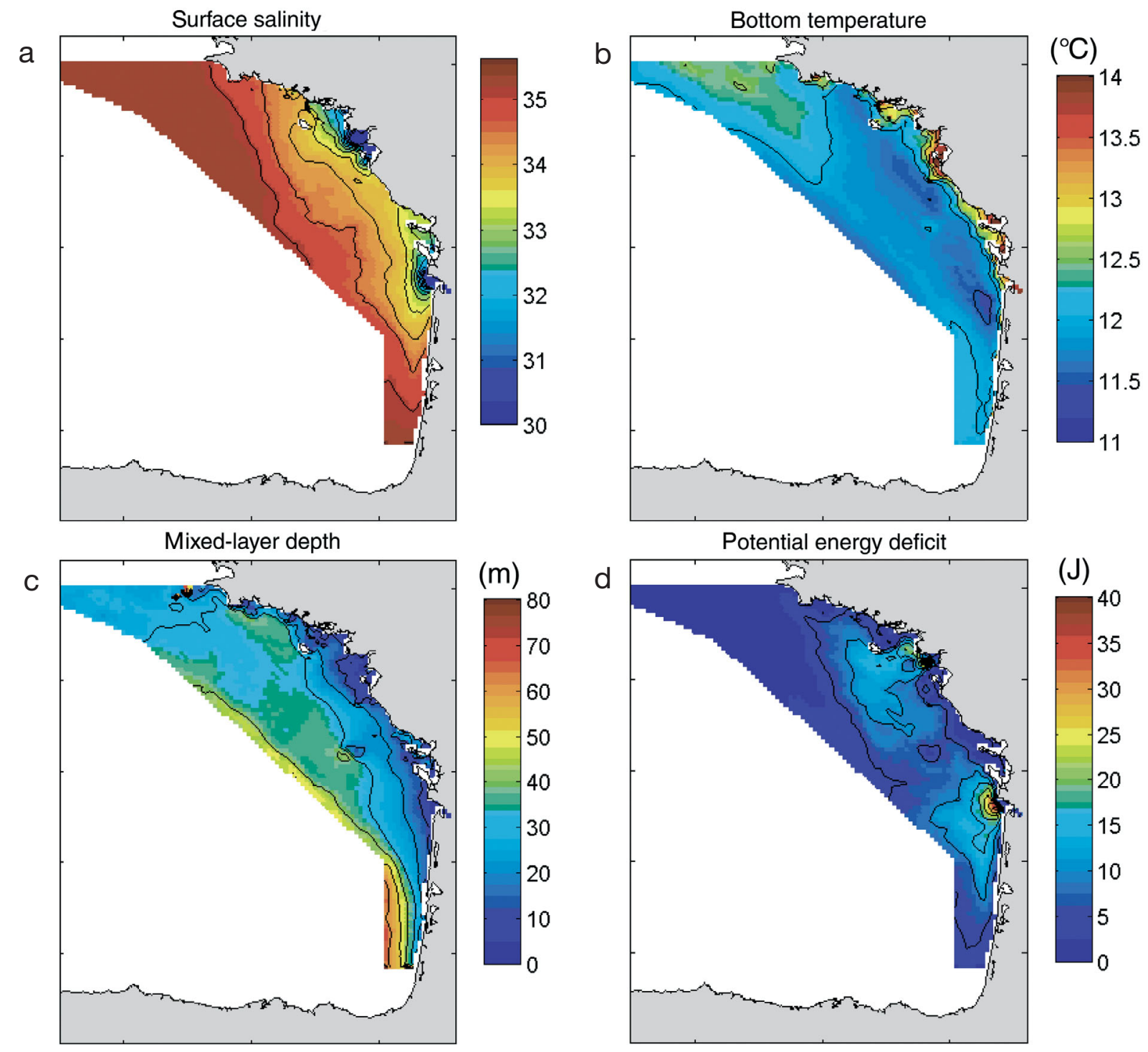

Fig. 2. Average spatial distribution of (a) surface salinity, (b) bottom temperature, (c) mixed-layer depth, and (d) potential energy deficit over the Bay of Biscay continental shelf in spring

\section{RESULTS}

\subsection{Climatologies}

Some of the main features of the Bay of Biscay hydrology in spring can be described from the average distribution of SS, BT, MLD and PED. SS (Fig. 2a) is characterised by a gradient from the coast towards the outer shelf, with 2 low salinity areas that correspond to the runoff from the main rivers along the French Atlantic coast, the Loire (North) and Gironde (South). BT (Fig. 2b) can be separated into 3 regions: (1) the northern part of the shelf, where BT is above $12^{\circ} \mathrm{C}$ on average; (2) a large part of the shelf, where BT remains low; and (3) a thin coastal strip where low depth and tidal mixing contribute to increased temperature at the bottom. Averaged MLD (Fig. 2c) nearly follows the bathymetry of the shelf. Potential energy deficit (Fig. 2d) is related to haline stratification, thermal stratification and tidal mixing. This parameter delineates extended river plumes, the coastal strip and the northern area of the shelf.

\subsection{Optimal number of hydrological landscapes}

The partitioning of spring hydrodynamics into a set of separated landscapes was attempted with landscapes ranging in number from 2 to 10 . The criteria calculated for the best number of partitions was the Davies-Bouldin index. It is apparent from Fig. 3 that there is little difference between the Davies-Bouldin 


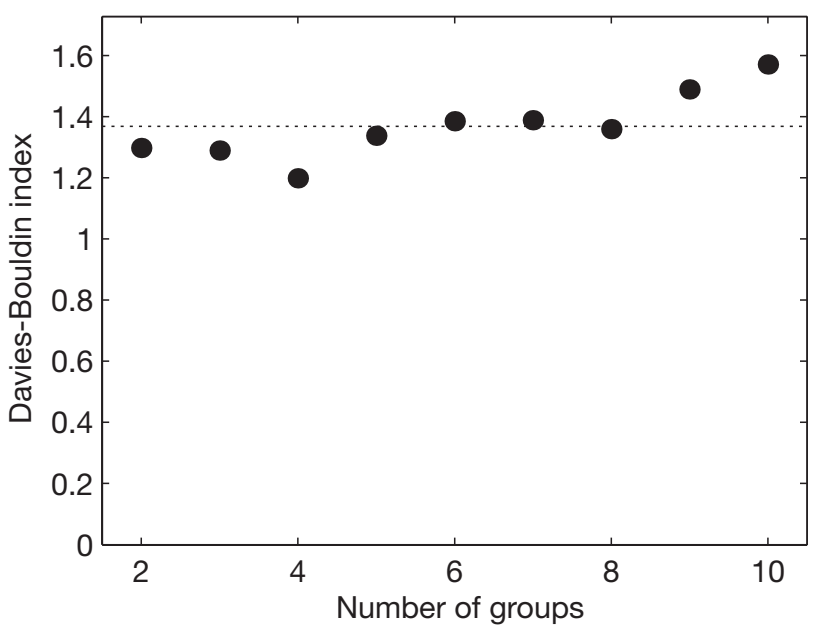

Fig. 3. The Davies-Bouldin index of partitioning efficiency against the number of groups (landscapes). Lower index values indicate better partition. Dotted line shows the mean value of the index

index values, and the choice of an optimal number of hydrological landscapes on a numerical basis is not obvious. The lowest value of the index was for 4 groups. However, when only 4 groups were retained, these were organised almost exclusively along the SS gradient, and provided little additional information to that of the SS field. The second apparent trough in the series of indices was for 8 groups. We kept this partition as it is consistent with previous results obtained by Planque et al. (in press) on a more limited dataset (for year 2000). Nonetheless, because modelled hydrological processes are organised along a spatial gradient rather than separated by clear boundaries, it is unlikely that any objective numerical analysis will provide a unique optimal number of groups to retain. This has to be selected based on other considerations, in particular the ability to interpret the groups obtained.

\subsection{Geographical distribution of hydrological landscapes and their characteristics}

The $K$-means partitioning analysis resulted in the construction of annual maps of distribution for the 8 landscapes. From these 15 annual maps, a summary map was constructed, showing for each geographical location the most frequently observed hydrodynamic landscapes (Fig. 4a). The characteristics of each landscape (i.e. temporal changes in SS, BT, MLD and PED) are indicated in Fig. $4 \mathrm{~b}$. The 8 landscapes can be described as follows:
(1) High estuary. This landscape is located in the Loire and Gironde rivers and has a very restricted spatial extent. Compared to the other landscapes, it is characterised by the lowest (and increasing) SS, an increase in BT during the season from the lowest to the highest values, a very shallow MLD (linked to shallow bathymetry) and a high stratification (PED) throughout spring.
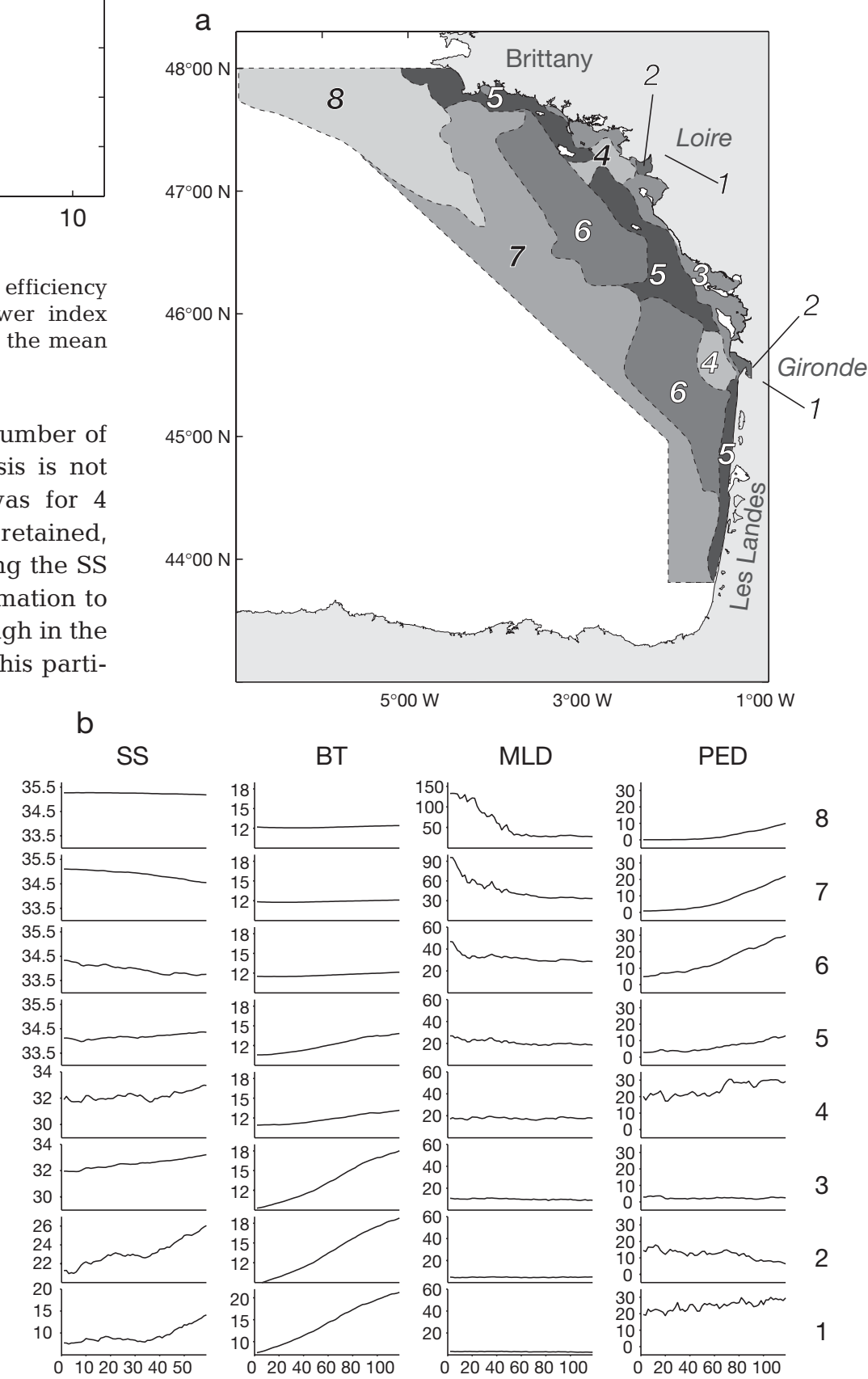

Fig. 4. Spatial distribution of (a) the 8 spring hydrodynamic landscapes, and associated time series and (b) surface salinity (SS), bottom temperature $\left(\mathrm{BT},{ }^{\circ} \mathrm{C}\right)$, mixed-layer depth (MLD, $\left.\mathrm{m}\right)$, and potential energy deficit (PED, J). The groups are, from bottom to top: (1) high estuary, (2) low estuary, (3) coastal, (4) river plume, (5) near coastal, (6) central shelf, (7) open shelf, and (8) northwestern shelf 
(2) Low estuary. This landscape is found close to high estuary but further downstream and has an equally restricted spatial extent. Its characteristics are similar to those of the high estuary but are less extreme. SS is low, increase in BT is strong, MLD is shallow, and PED is high but decreases during the season.

(3) Coastal. Located along a thin strip between the Loire and Gironde and north of the Loire, its characteristics are similar to but less marked than those of the estuarine landscapes. A major difference is the drop in PED and increase in MLD (up to local bathymetry values), which reflects intense vertical mixing in these areas.

(4) River plume. This landscape is found in shallow water in front of the Loire and Gironde river mouths. With an SS of around 32, it represents the shelf extension of the Loire and Gironde rivers. It has the strongest stratification (highest PED), which increases during the season (as a result of solar heating), while the MLD is maintained around $20 \mathrm{~m}$. The strong stratification results in a decoupling between upper and deeper layers, which is apparent in the low increase in BT observed.

(5) Near coastal. This landscape is situated along the coast in the southern part of the Bay of Biscay (coast of Les Landes) and in the northern part of the Bay (southern Brittany), and along a strip further off shore in the mid-latitudes of the Bay. SS is higher than in the previous landscapes; the increase in temperature is slightly more marked than that of the river plume hydrodynamics and the PED is low but increasing (thermal stratification).

(6) Central shelf. Characterised by fairly stable temporal dynamics, this landscape displays little variation in the 4 hydrological parameters. The SS $(<34.5)$ still reflects the influence of fresh water outflow. The increasing PED indicates the presence of thermal stratification. The deep and little varying MLD (around $30 \mathrm{~m}$ ) reflects stability in the vertical structures, which is also seen in the restricted variations in BT. This landscape corresponds to a robust vertical structure which is little altered during spring.

(7) Open shelf. This landscape is found over the deeper area of the shelf towards the continental slope. The SS remains close to that of oceanic water (35.5) during spring, and only a slight decrease in salinity indicates the weak influence of fresh water runoff. Stratification is mostly driven by solar heating, and average MLD decreases from 90 to $30 \mathrm{~m}$ and PED increases from almost 0 to $20 \mathrm{~J}$. The transition from an unstratified to a stratified water column is completed around mid-April (Day 45 of simulation).

(8) Northwestern shelf. This landscape is located in a large area restricted to the northwest open shelf region and is connected to the Celtic Sea. It is the most 'open ocean' landscape, with no variations in SS, and almost no variations in BT. As for open shelf hydrodynamics, it is characterised by the fact that thermal stratification takes place during the first $40 \mathrm{~d}$ of the season (1 March to mid-April).

\subsection{Inter-annual stability of group characteristics}

The 8 landscapes identified and described above correspond to average situations constructed from the entire dataset, i.e. $15 \mathrm{yr}$ of data. Although it is likely that some features may be recurrent from year to year, others may be unusual or exceptional and therefore not well captured by the hydrological landscapes above. Thus, it is important to evaluate the representativeness of these landscapes for each individual year. This is done by comparing the characteristics of each landscape averaged over the $15 \mathrm{yr}$ with the characteristics of the landscapes in individual years. The comparison was realised by means of MDS analysis. In this analysis, landscapes are plotted on a 2D plane, and landscapes that are located nearby are more similar than landscapes located far apart. The MDS plot shows that the scatter of individual years around the average situation (over $15 \mathrm{yr}$ ) of each landscape is generally small (Fig. 5). There is no overlap between hydro-

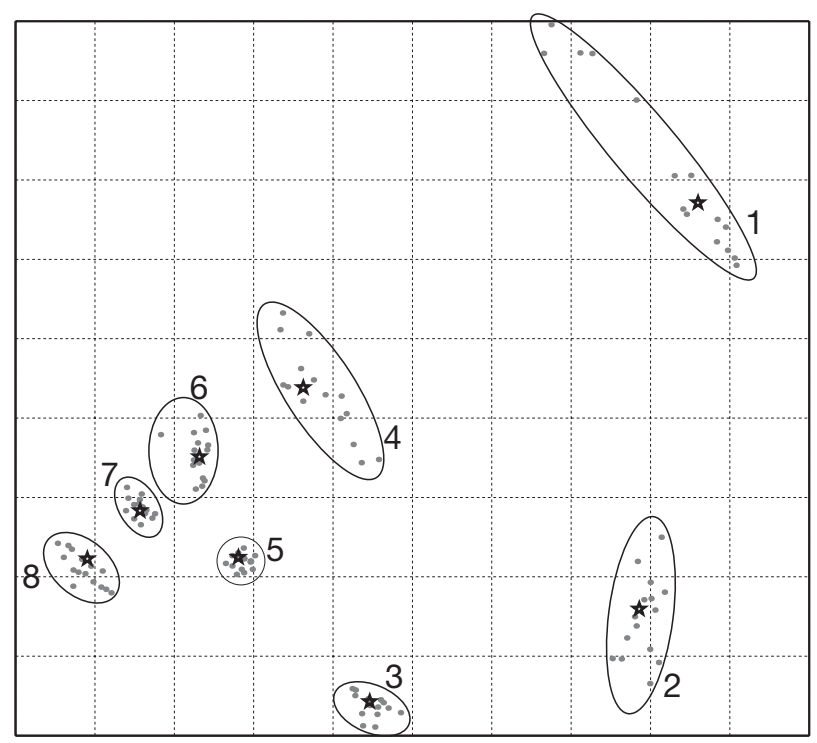

Fig. 5. Multi-dimensional scaling (MDS) analysis of the yearto-year variations in hydrodynamical landscapes characteristics. Each dot represents the characteristics of a hydrodynamical landscape in an individual year. Stars represent the characteristics of hydrodynamical landscapes averaged over the $15 \mathrm{yr}$ of simulation. The shorter the distance between landscapes in the MDS plane, the greater the similarity between these landscapes. Numbers refer to landscapes defined in Fig. 4 


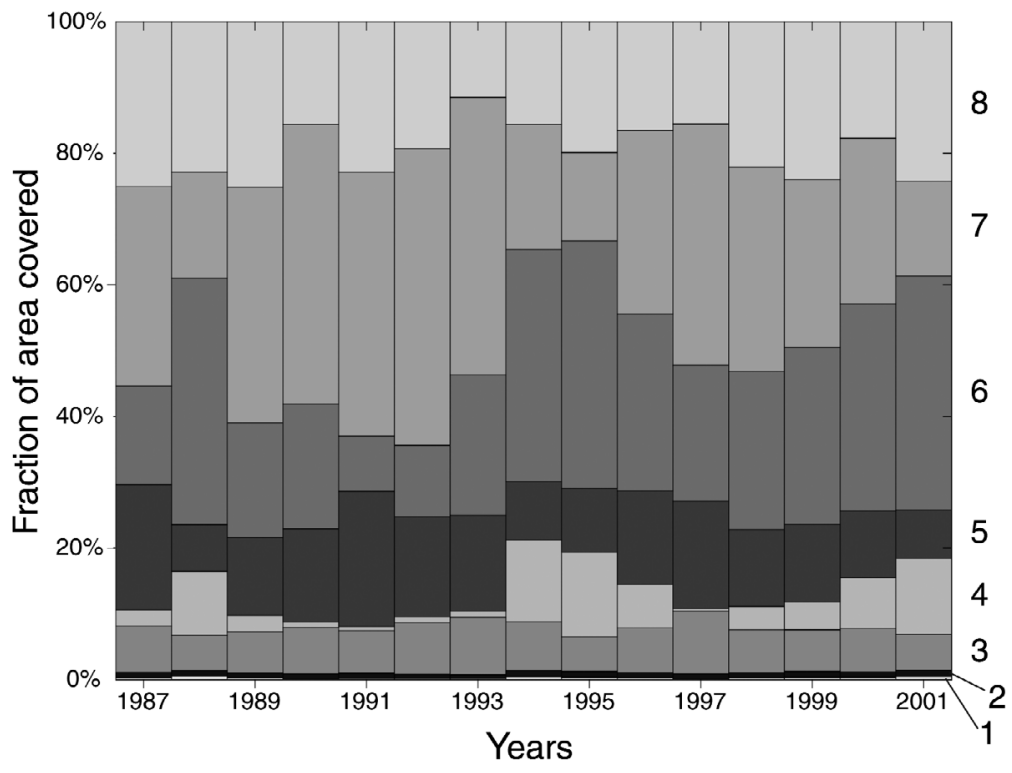

Fig. 6. Geographical extent of the 8 spring hydrodynamical landscapes against year of simulation. Height of bars is proportional to the area covered by each landscape. Numbers on the right side refer to landscapes as defined in Fig. 4

dynamical landscapes, and one can reasonably assume that the time-series shown in Fig. 4 are representative of the hydrodynamics in each year. Two landscapes are more scattered: the high and low estuaries. This is probably explained by the very small surface covered by these landscapes and their strong dependence upon the local runoff conditions. The MDS plot provides additional information on the relationships between landscapes. The high and low estuaries clearly diverge from the other landscapes and are far from each other. The coastal landscape is also detached from the 5 remaining landscapes, which are well individualised. The position of these 5 landscapes in the 2D MDS space follows approximately a gradient from the coast towards the shelf break waters. ered by high and low estuary waters (Landscapes 1 and 2) are almost imperceptible since the 2 landscapes have a very restricted spatial extent. The coastal landscape (Landscape 3) is a common feature of all years and displays little variation in its spatial extent. On the other hand, the geographical extent of river plumes (Landscape 4) is greatly variable, and the area covered by this landscape can vary 33-fold. Near coastal (Landscape 5), central shelf (Landscape 6), open shelf (Landscape 7) and northwestern shelf waters (Landscape 8) cover the major part of the shelf. They display large amplitude variations in their geographical coverage with a max./min. ratio of spatial extent of 2.8, 4.5, 3.3 and 2.2 respectively.

Despite great differences in the amplitude of inter-annual variations in geographical coverage between landscapes, it is likely that these fluctuations are inter-related since the 8 landscapes share a common fixed geographical space (i.e. increase in spatial extent of one landscape can only be achieved if space is made available by retraction of other landscapes). The relationships between year-to-year changes of the extent of landscapes can be simply measured by correlation analysis. The results from this analysis (Table 1) show a great degree of correlation between the landscapes, with $2 / 3$ of the correlation coefficients being significant at either 1 or $5 \%$ levels. This suggests that there is possibly a common driving force which governs the interannual changes in spring hydrodynamics over most of the Bay of Biscay shelf. It also suggests that most of the variability in the extent of the hydrological landscapes may be summarised by a 1-dimensional index.

Such an index can be calculated using PCA performed on the data table used to construct Fig. 6. The

\subsection{Year-to-year fluctuations in hydrodynamic pattern}

In the previous section it was shown that the 8 landscapes defined are representative of the hydrodynamics over the Bay of Biscay shelf for all years of simulation. However, the spatial extent of individual hydrological landscapes can vary greatly from year to year, as shown in Fig. 6. Each year, individual hydrological landscapes occupy a fraction of the total surface covered in this study $(71 \times$ $10^{3} \mathrm{~km}^{2}$ ). Changes in the surface cov-
Table 1. Pearson correlation coefficient between time series of changes in spatial extent of the 8 hydrodynamical landscapes. Level of significance is $1 \%$ (bold), $5 \%$ (bold-italics) and not-significant (others). No correction for autocorrelation was applied to the test, since no significant positive autocorrelation was detected in any of the series

\begin{tabular}{|lrrrrrrr|}
\hline & $\begin{array}{c}\text { High } \\
\text { estuary }\end{array}$ & $\begin{array}{c}\text { Low } \\
\text { estuary }\end{array}$ & $\begin{array}{c}\text { River } \\
\text { plume }\end{array}$ & Coastal & $\begin{array}{c}\text { Near } \\
\text { coastal }\end{array}$ & $\begin{array}{c}\text { Central } \\
\text { shelf }\end{array}$ & $\begin{array}{c}\text { Open } \\
\text { shelf }\end{array}$ \\
\hline Low estuary & $\mathbf{0 . 6 5}$ & & & & & & \\
River plume & $\mathbf{- 0 . 6 6}$ & $\mathbf{- 0 . 5 9}$ & & & & & \\
Coastal & $\mathbf{0 . 8 6}$ & $\mathbf{0 . 7 2}$ & $\mathbf{- 0 . 6 0}$ & & & & \\
Near coastal & $\mathbf{- 0 . 8 1}$ & -0.43 & $\mathbf{0 . 5 2}$ & $\mathbf{- 0 . 8 0}$ & & & \\
Central shelf & $\mathbf{0 . 8 2}$ & $\mathbf{0 . 6 2}$ & -0.47 & $\mathbf{0 . 9 1}$ & $\mathbf{- 0 . 8 8}$ & & \\
Open shelf & $\mathbf{- 0 . 9 0}$ & $\mathbf{- 0 . 8 2}$ & $\mathbf{0 . 6 6}$ & $\mathbf{- 0 . 9 4}$ & $\mathbf{0 . 7 5}$ & $\mathbf{- 0 . 9 0}$ & \\
Oceanic & 0.38 & 0.40 & $\mathbf{- 0 . 6 6}$ & 0.10 & -0.07 & -0.06 & -0.30 \\
\hline
\end{tabular}




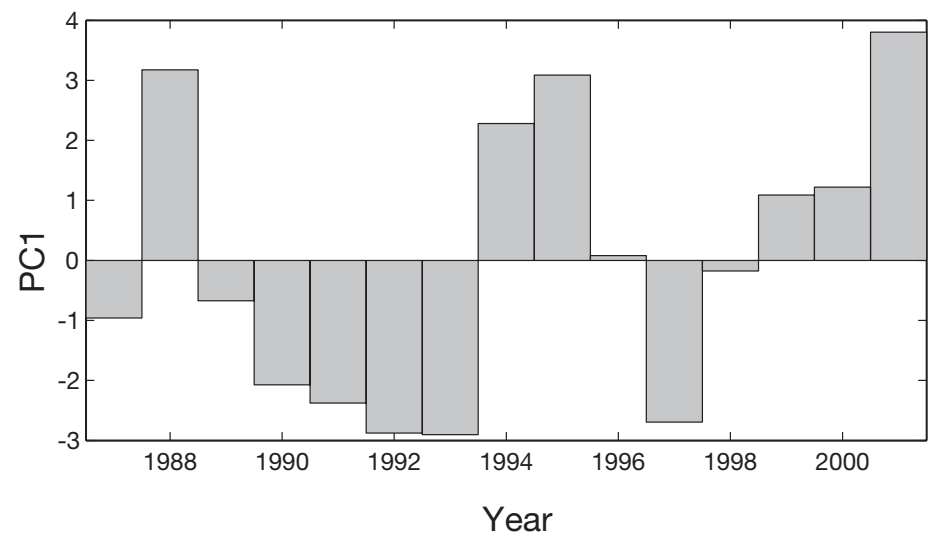

Fig. 7. Summary index for the Bay of Biscay continental shelf spring hydrodynamics: the first principal component (PC1) from the PCA analysis of the time-series in Fig. 6

result of the PCA shows that $69 \%$ of the variance is represented in the first axis. Year-to-year fluctuations in the values of the first component are shown in Fig. 7. The second axis accounts for $18 \%$ of the variance, and the last $13 \%$ is shared between the remaining 6 axes. The first axis is highly correlated with all hydrological landscapes, except the northwestern shelf (correlation coefficients for Landscapes 1 to 8 are: $0.94,0.80,-0.75$, $0.94,-0.84,0.90,-0.97$ and 0.34$)$. The second axis is strongly associated with the northwestern shelf landscape (correlation coefficient: 0.90), indicating that the inter-annual variations in the northwestern shelf landscape are almost totally independent from those of other landscapes.

\section{DISCUSSION}

Some of the major characteristics of the hydrology over the Bay of Biscay continental shelf have been described in a review by Koutsikopoulos \& Le Cann (1996). The major features they identified in spring and early summer consisted of river plumes, upwellings along the coast of 'Les Landes', slope fronts, and a large area of cold (bottom) water masses which they termed the 'cold pool'. Recently, Puillat et al. (2003) described in more details the role of river plumes on the shelf hydrodynamics and in particular the setting of mid-shelf freshwater lenses detaching from the river plumes when specific wind conditions occur.

There are 2 major differences between the work conducted by Koutsikopoulos \& Le Cann (1996) and Puillat et al. (2003) and the analysis presented here. First, we have based our identification of hydrological landscape on temporal changes in hydrology. This is distinct from the above studies in which it is the differences in static hydrological situations (typically, indi- vidual hydrological vertical profiles) that were used to describe hydrological features. Second, we have based this study on model simulations rather than observations. This results in differences in the nature and the geographical extent of the structures observed.

\subsection{Cold pool}

The 'cold pool' is not described as such in this study, but it can be represented by the association of northwestern shelf, open shelf and central shelf hydrological landscapes, which display minor increase in BT during spring. The spatial extent of these 3 landscapes is greater than that described for the cold pool with cold landscapes found closer to the coast and much further south.

\subsection{River plumes}

The river plumes described in Koutsikopoulos \& Le Cann (1996) encompass the landscapes termed 'river plume' and 'coastal' in this study. It is interesting to note that although close geographically and with similar SS, these 2 entities have clearly distinct spring hydrodynamics (Figs. 4 \& 5): in river plumes vertical mixing is weak and BT remains low, whilst in coastal waters vertical mixing is intense and BT increases following solar heating. We have not identified structures which could be termed freshwater lenses, as in Puillat et al. (2003). This may result from the fact that these structures resemble river plumes and have high spatial dynamics during spring, as they tend to have a short life and move rapidly over the shelf. They may be included in the river plume hydrodynamical landscape, and their presence may be reflected in the geographical extent and the shape of the plumes.

\subsection{Coastal upwellings}

The hydrodynamic model can reproduce the coastal upwellings (e.g. Allain et al. 2001), but these structures are not identified as such in this study. The area along the coast of Les Landes where spring upwelling is known to occur is grouped with 2 other areas, one located between the Loire and Gironde river plumes and the other along the south coast of Brittany. Recent observations have shown that upwelling also occurs south of Brittany (Puillat et al. in press), but this feature was not described in Koutsikopoulos \& Le Cann (1996). 


\subsection{Central shelf}

This landscape was first identified in a similar study restricted to 1 mo model simulation in 2000 (Planque et al. in press). The main characteristic of this landscape is its stability during spring. The hydrodynamics over most of the shelf is affected by temporal decrease in river runoff and/or increase in solar heating. Over the central shelf area, this is expressed by a persistent increase in vertical stratification (up to the highest values recorded) with little change in SS and BT. The MLD is maintained at almost half the bottom depth throughout spring.

Although there is great variety in the structures described, we have shown that it is possible to summarise the year-to-year variability in hydrological landscapes - at least the variability in their spatial extent - by using a single indicator. This is achievable with the above PCA if the northwestern shelf area is excluded from the analysis. Changes in the spatial extent of hydrological landscapes are strongly interrelated, and it appears reasonable to postulate that a common single factor can drive these changes. One obvious candidate is river runoff, since it is known to be a factor of influence on the hydrology over the continental shelf, and it displays great year-to-year variability (Planque et al. 2003). We compared changes in the runoff from the Loire river with those of the first principal component. Because runoff is measured in the river, we allowed a lag of 2 mo between the period of runoff measurements and that of hydrological simulation to allow for the effects of runoff anomalies to propagate over the shelf. The runoff anomalies are therefore calculated over the months January to April. Anomalies in runoff from the Loire are closely related to anomalies in the major river of the French Atlantic coast: the Gironde (Planque et al. 2003). They can therefore be considered as a proxy for the total runoff over the shelf. The comparison of runoff and first principal component (Fig. 8) reveals a strong linear relationship between the 2 indices. Winter-spring anomalies in Loire runoff accounts for $91 \%$ of the variability in the first principal component. We can conclude from this simple analysis that the major forcing factor behind the extent of spring hydrological landscapes in the Bay of Biscay is the volume of river discharge during this period and in the preceding months. Precipitation is related to atmospheric circulation patterns, with higher precipitation generally associated with low pressure cyclonic systems over the Bay of Biscay. It is thus likely that river discharge also partly acts as a proxy for wind forcing.
One major question which arises from the results here is the ability of the model to faithfully represent the hydrodynamics over the Bay of Biscay continental shelf. We have intentionally restricted our analysis to the study of model output rather than that of field data, and have therefore not investigated the validity of the model in mimicking such structures. The model has already been used to provide hydrological and hydrodynamical fields in a number of studies (e.g. Hermida et al. 1998, Castaing et al. 1999, Boutier et al. 2000, Allain et al. 2001, 2003, Labry et al. 2001b, Loyer et al. 2001a, Le Pape et al. 2003). In these studies, the model outputs were compared with either in situ or satellite observations and suggest that the hydrological fields provided by the model constitute a good proxy for the true hydrography over the Bay of Biscay continental shelf.

Obviously, interannual variability in shelf hydrodynamics resulting from large-scale circulation and off-shelf transport will not be represented in the current study, since variability in off-shelf hydrological conditions are not taken into account to this model. On the other hand, it is likely that structures primarily affected by river runoff and surface winds will be well described.

The methodology proposed here is not limited to the current state of the hydrodynamic model and will still be applicable after any modification in the model. In addition, the model output parameters have been selected so that they can also be observed in the field. The analysis

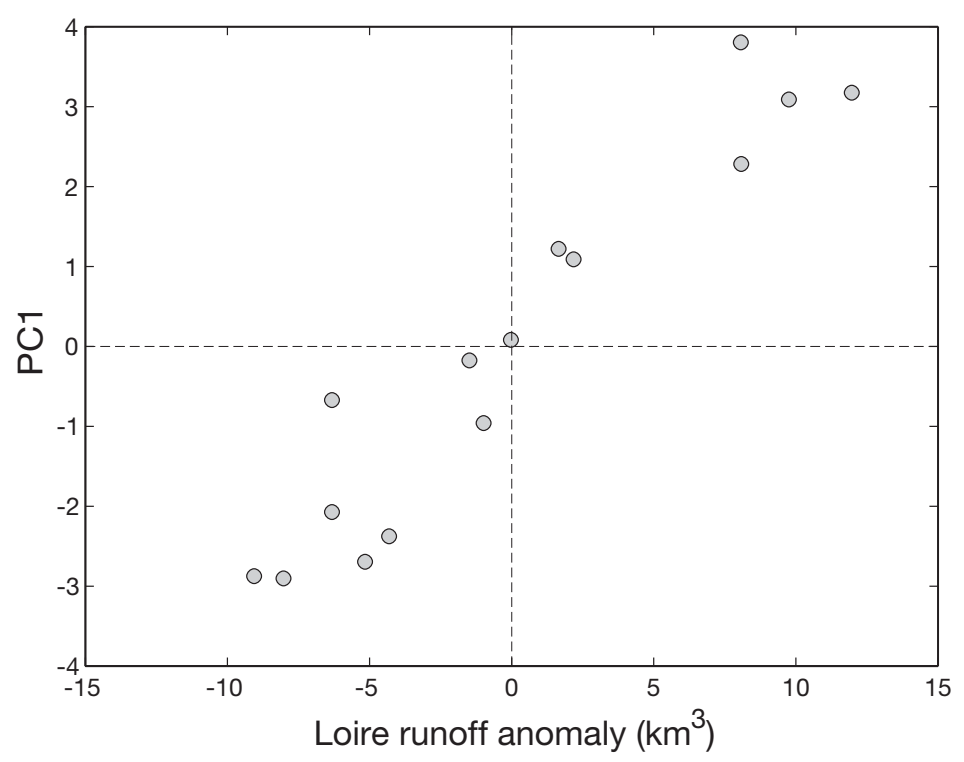

Fig. 8. Summary index for the Bay of Biscay (as in Fig. 7) plotted against anomalies in winter-spring runoff from the Loire river (1987 to 2001). Anomalies are calculated as the difference between runoff in a given year and runoff averaged over the period 1987 to 2001. PC1: first principal component 
proposed here is therefore designed in a way that makes it applicable to observed data, as long as these consist of series of vertical hydrological profiles during spring. The method can also be easily transferred to the study of hydrodynamics patterns in other seasons.

One advantage of the model-based analysis of hydrological landscape is the scope of the method for hind-, now- and forecasting. Reconstructing the geography of past spring hydrodynamics from field data is often difficult because of the limited number of past hydrological observations available. Similarly, nowcasts are difficult to produce from field data because cruise sampling plans do not generally allow for synoptic hydrological observation over a large areas, and hydrological parameters vary during the time of the cruise. This can lead to misrepresentation of the hydrological geographical entities as shown in Ibanez (1973) and Planque et al. (in press). Under the assumption that external forcing parameters (wind and river runoff) are known and that the model is reasonably accurate, it is possible to produce hindcasts and nowcasts of the shelf hydrodynamics patterns. Forecasting is also conceivable, but it will be heavily dependent upon the ability to reliably predict future river runoff and wind fields.

The spatial location of the hydrological landscapes defined in this study will have direct implications for the biological dynamics over the shelf. This is true, first, because the amount of river runoff combined with vertical stratification mostly control the distribution of river turbidity plumes (Castaing et al. 1999), which in return affect light penetration and bottom substrate. Second, the late-winter/spring primary production in the Bay of Biscay is partly controlled by nutrient loading of anthropogenic origin (Loyer et al. 2001b) but also by a combination of solar radiation and the onset of haline and thermal stratification (Labry et al. 2001a, Gohin et al. 2003), the latter being well captured by the current methodology.

\section{CONCLUSIONS}

The methodology presented here allows for the objective definition of spring hydrological landscapes over the Bay of Biscay shelf. Eight landscapes, which are found every year but with varying spatial extents, have been defined: high estuary, low estuary, coastal, river plume, near coastal, central shelf, open shelf, and northwestern shelf. The spatial extent of these landscapes is primarily influenced by the amount of river runoff during the period January to April.

Spatial distributions of biological processes such as primary and secondary production, spawning, feeding or nursery areas for specific pelagic species can easily be compared with the spatial extent of the hydrological landscapes. Hence, the definition of these landscapes constitutes a useful step towards defining plankton and fish pelagic habitats in the Bay of Biscay.

Acknowledgements. This work has been supported by Ifremer Bay of Biscay project and the French national programme on coastal environment (PNEC). It is part of the Forevar project (meso-scale environmental forcing and variability of pelagic populations in the Bay of Biscay).

\section{LITERATURE CITED}

Allain G, Petitgas P, Lazure P (2001) The influence of mesoscale ocean processes on anchovy (Engraulis encrasicolus) recruitment in the Bay of Biscay estimated with a threedimensional hydrodynamic model. Fish Oceanogr 10: 151-163

Allain G, Petitgas P, Grellier P, Lazure P (2003) The selection process from larval to juvenile stages of anchovy (Engraulis encrasicolus) in the Bay of Biscay investigated by Lagrangian simulations and comparative otolith growth. Fish Oceanogr 12:407-418

Bakun A (1996) Patterns in the ocean. Ocean processes and marine population dynamics. NOAA, California Sea Grant College System, La Jolla, CA

Beaugrand G, Reid PC, Ibañez F, Lindley JA, Edwards M (2002) Reorganization of North Atlantic marine copepod biodiversity and climate. Science 296:1692-1694

Boutier B, Chiffoleau JF, Gonzalez JL, Lazure P, Auger D, Truquet I (2000) Influence of the Gironde estuary outputs on cadmium concentrations in the coastal waters: consequences on the Marennes-Oléron bay (France). Oceanol Acta 23:754-757

Castaing P, Froidefond JM, Lazure P, Weber O, Prudhomme R, Jouanneau JM (1999) Relationship between hydrology and seasonal distribution of suspended sediments on the continental shelf of the Bay of Biscay. Deep-Sea Res II 46:1979-2001

Davies DL, Bouldin DW (1979) A cluster separation measure. IEEE (Inst Electr Electron Eng) Trans Pattern Anal 1: $224-227$

Gohin F, Lampert L, Guillaud JF, Herbland A, Nézan E (2003) Satellite and in situ observations of a late winter phytoplankton bloom, in the northern Bay of Biscay. Cont Shelf Res 23:1117-1141

Hermida J, Lazure P, Froidefond JM, Jégou AM, Castaing P (1998) Seaward dispersion of Gironde estuarine waters on to Aquitanian continental shelf from hydrological, satellite and numeric data. Oceanol Acta 21:209-221

Ibanez F (1973) Méthode d'analyse spatio-temporelle du processus d'échantillonnage en Planctologie, son influence dans l'interprétation des données par l'analyse en composantes principales. Ann Inst Océanogr 49:83-111

Jain AK, Dubes RC (1988) Algorithms for Clustering Data. Prentice Hall, Englewood Cliffs, NJ

Koutsikopoulos C, Le Cann B (1996) Physical processes and hydrological structures related to the Bay of Biscay anchovy. Sci Mar 60(Suppl2):9-19

Kruskal JB (1964) Nonmetric multidimensional scaling: a numerical method. Psychometrica 29:1-27

Labry C, Herbland A, Delmas D, Laborde P, Lazure P, Froidefond JM, Jegou AM, Sautour B (2001a) Initiation of winter phytoplankton blooms within the Gironde plume waters in the Bay of Biscay. Mar Ecol Prog Ser 212:117-130

Labry C, Herbland A, Delmas D, Laborde P, Lazure P, Froidefond JM, Jégou AM, Sautour B (2001b) Winter phytoplankton blooms within the Gironde plume waters in the 
Bay of Biscay. In: Elbée J, Prouzet P (eds) Océanographie du golfe de Gascogne. VIIe Colloq. Int. Ifremer, Actes Colloq., Biarritz, 4-6 avril 2000. IFREMER, Brest, p 137-139

Lazure P, Jégou A-M (1998) 3D modelling of seasonal evolution of Loire and Gironde plumes on Biscay bay continental shelf. Oceanol Acta 21:165-177

Le Cann B (1990) Barotropic tidal dynamics of the Bay of Biscay shelf: observations, numerical modelling and physical interpretation. Cont Shelf Res 10:723-758

Leendertse JJ (1970) A water quality simulation model for well-mixed estuaries and coastal seas, Vol 1. Principles of computations. The Rand Corporation RM-6320-RC:71. The Rand Corporation, Santa Monica, CA

Legendre P, Legendre L (1998) Numerical ecology. Elsevier, Amsterdam

Lehodey P, Bertignac M, Hampton J, Lewis A, Picaut J (1997) El Niño Southern Oscillation and tuna in the western Pacific. Nature 389:715-718

Le Pape O, Chauvet F, Mahévas S, Lazure P, Guérault D, Désaunay Y (2003) Quantitative description of habitat suitability for the juvenile common sole (Solea solea) in the Bay of Biscay (France) and the contribution of different habitats to the adult population. J Sea Res 50:139-149

Loyer S, Lazure P, Lampert L (2001a) Primary production model of the Bay of Biscay. Littoral zones and anthropization: management and nuisance. J Rech Océanogr 26:153

Loyer S, Lazure P, Menesguen A, Lampert L, Druon JN (2001b) Primary production model of the bay of Biscay. In: Elbée J, Prouzet P (eds) Océanographie du golfe de Gascogne. VIIe Colloq. Int. Ifremer, Actes Colloq., Biarritz, 4-6 avril 2000. IFREMER, Brest, p 105-113
Luyten PJ, De Mulder T (1992) A module representing surface fluxes of momentum and heat. Technical Report No 9 MAST-0050-C (MUMM)

Mann KH, Lazier JRN (1991) Dynamics of marine ecosystems. Biological-physical interactions in the oceans. Blackwell Scientific Publications, Oxford

Pingree RD, Le Cann B (1989) Celtic and Armorican slope and shelf residual currents. Prog Oceanogr 23:303-338

Planque B, Beillois P, Jégou AM, Lazure P, Petitgas P, Puillat I (2003) Large scale hydroclimatic variability in the Bay of Biscay. The 1990s in the context of interdecadal changes. ICES Mar Sci Symp 219:61-70

Planque B, Lazure P, Jégou AM (in press) Typology of hydrological structures modelled and observed over the Bay of Biscay shelf. Sci Mar

Puillat I, Lazure P, Jégou AM, Planque B, Lampert L (2003) Mesoscale, interannual, and seasonal hydrological variability over the French continental shelf of the Bay of Biscay during the 1990s. ICES Mar Sci Symp 219:333-336

Puillat I, Lazure P, Jégou AM, Lampert L, Miller P (in press) Mesoscale hydrological variability induced by northwesterly wind on the French continental shelf of the Bay of Biscay. Sci Mar

Reynaud T, Legrand P, Mercier H, Barnier B (1998) A new analysis of hydrographic data in the Atlantic and its application to an inverse modelling study. Int WOCE Newsl 32:29-31. Available at: ftp://ftp.soc.soton.ac.uk/ pub/woceipo/newsl/news32.pdf

Schwiderski EW (1980) Ocean tides, Part II. A hydrodynamical interpolation model. Mar Geod 3:219-255

Appendix 1. Hydrodynamic model of the Bay of Biscay, MARS3D

MARS3D is a finite difference free surface model. It uses sigma coordinates and a mode splitting technique. The external mode is solved according to an ADI scheme (Alternate Direction Implicit, Leendertse 1970). An original iterative procedure is used for the coupling with the internal mode.

\section{Model configurations}

The domain extends in longitude from the French coast to $8^{\circ} \mathrm{W}$ and in latitude from the Spanish coast to $49^{\circ} \mathrm{N}$. For the current application, it was restricted to the shelf, (the open boundary is limited to the $200 \mathrm{~m}$ depth approximately). Bathymetry was provided by SHOM (Service Hydrographique de la Marine). The model has a grid size of $5 \mathrm{~km}$ and uses 10 sigma levels. To reproduce hydrological features in the surface layer, sigma level distribution was denser near the surface. Open boundary conditions were calculated using a wider barotropic model.

\section{Boundary conditions}

A large 2D model extending from Portugal to Iceland was used to provide boundary conditions to the 3D model. Tidal constituents along the open boundary of the large model were extracted from the Schwiderski atlas (1980). Because hindcasts of meteorological fields for the last $50 \mathrm{yr}$ are not yet available, the winds were provided by 3-hourly measurements made at the lighthouse in Oléron. This approximation is partly justified by the relative spatial homogeneity of the wind field at a time scale greater than a week, as shown by Pingree \& Le Cann (1989) and Lazure \& Jegou (1998) when comparing progressive vector diagrams at different locations along the coast. The 3D model was forced by free surface elevation, and a radiation condition was used for the velocity along the open boundary. Surface heat fluxes were calculated with bulk formulae (Luyten \& De Mulder 1992), which involves wind speed, air temperature, nebulosity, and relative humidity. The first parameter was provided by meteorological measurements, whereas climatological values were used for the 3 latter variables. Temperature and salinity at the open boundary were taken from the Reynaud climatology (Reynaud et al. 1998). Loire, Gironde and Adour river runoffs were obtained from daily measurements in each individual estuary.

\section{Initial conditions}

Currents were set to zero at the beginning of the simulation, and the free surface elevation was interpolated in the domain from values at open boundary conditions. The spin up time for tidal dynamics and any gravity waves is rather short because of their high velocities: the order of magnitude was $5 \mathrm{~d}$ in that configuration. A homogenous salinity of 34.5 and a temperature of $11^{\circ} \mathrm{C}$ over the whole domain was chosen. This unrealistic thermal structure over the shelf is nevertheless close to the one showed by climatologies during winter. Under these conditions, a 1 yr spin up is enough for the memory of these rather unrealistic initial conditions to be lost. The modelled shelf hydrological system is a rather short memory system, which recovers from these initial conditions within a year. In the current study, the model spin up spanned 1985-1986 and model simulation outputs were considered from 1987 onwards. 
Appendix 1 (continued)

\section{Tidal dynamics}

A realistic tidal evolution of free surface was composed from the 8 tidal constituents (M2, S2, K2, N2, 01, K1, P1, and Q1) of the Schwiderski atlas (1980). From a 1 yr analysis, a harmonical analysis was used to extract the main tidal constituents (amplitude and phase) for the 8 waves at each point of the domain. This allowed a comparison with tidal constituents which are well known in some harbours along the coast (list given in Le Cann 1990). A comparison over the whole continental shelf has also been done with a recent database constructed by SHOM. This harmonic database included 115 constituents and was constructed on the basis of a 2D barotropic model with adjustments being made for existing measurements. It covered the continental shelf of the Bay of Biscay and the English Channel. Average differences over most of the domain were less than $20 \mathrm{~cm}$. The increase in this difference in the Gironde estuary was due to the domain limitation. No attempt has been made to improve the tidal propagation in the Gironde River, as the mesh size $(5 \mathrm{~km})$ is not suitable to accurately describe this propagation. Differences between model and results also increase near islands, e.g. north of the Gironde estuary and around the Loire estuary. These discrepancies may be due to local effects (i.e. spatial extent less than $5 \mathrm{~km}$ ). Time differences between model and measurements were less than 20 min over the shelf. These comparisons of computed and predicted free surface elevation show that the model accurately reproduces the tidal propagation and allow us to describe tidal currents which have 2 effects on hydrology: advection and mixing.

\section{Tidal currents}

Model outputs displayed large spatial gradients in maximum tidal velocity. In the northern part, tidal currents exceeded $1 \mathrm{~m} \mathrm{~s}^{-1}$ during spring tides whereas they hardly reached $0.2 \mathrm{~cm} \mathrm{~s}^{-1}$ in the southern part of the Bay.

\section{Tidal Eulerian residual currents}

Tidal currents were locally averaged during a tidal cycle to evaluate Eulerian residual currents. Over most of the shelf and the deep part of the Bay of Biscay, residual currents are very weak (less than $1 \mathrm{~cm} \mathrm{~s}^{-1}$ ). Near the coast, especially around islands, these currents can be significantly higher, but the spatial resolution of the model is not suited for a description of residual currents in such conditions. Residual currents increase in the northern part of the Bay and west of Brittany. Several gyre related to bathymetry are generated. In these regions, velocity can reach up to $10 \mathrm{~cm} \mathrm{~s}^{-1}$ during an average tide.

\section{Coastal upwelling}

In general, the model shows a good agreement with observed surface temperature, and general features like the drop of isotherms near the coast (which result from upwelling) are well reproduced. At the coast, modelled temperature was between 14.5 and $15^{\circ} \mathrm{C}$, as seen in field measurements. Simulated surface layer depth was about $30 \mathrm{~m}$ and temperature on the shelf about $16^{\circ} \mathrm{C}$. These values are consistent with field observations.

\section{Salinity fields}

Simulated surface salinity fields reproduced most of the features observed during the 2 cruises, one in winter 1997-1998 and one in spring 1998. (1) There is a strip of salinity less than 35 which extends from the coast to about $100 \mathrm{~km}$ offshore in the north and $50 \mathrm{~km}$ offshore in the southern part of the Bay. (2) Off the Loire estuary, salinity decreases and the plume seems to extend to the south, with strong spatial gradient near Belle Ile Island. (3) In front of Gironde estuary, the plume is oriented toward the north. The vertical structure of a transect between south Brittany and Gironde estuary shows a good agreement with pycnocline depth at $30 \mathrm{~m}$ in both model and field observations. However, there can be some discrepancies between the modelled and the observed spatial extent of the plumes.

\section{Short conclusion}

Simulations and measurements showed good agreement. Barotropic tides were well reproduced, as is tidal mixing, which can be viewed as a structuring parameter like bathymetry. Its simulation is a necessary condition to investigate hydrology and its variability. There are some discrepancies in the spatial extent of the plumes which may be difficult to analyse without additional observations. Turbulence closure was satisfactory and the vertical structure was well reproduced for temperature and salinity. A complete evaluation of the model by comparisons with additional in situ measurements is still in progress.

Some other physical processes are currently being investigated. Internal tides are known to be strong in the northern part of the Bay of Biscay. They are generated at the top of the shelf edge and propagate on the 2 sides of the shelf. In the current version of the model these features are not reproduced, but a geographically more extended version of the model reproduces some internal movement of the pycnocline. However, the mesh size is still too large to accurately reproduce internal waves with wavelengths of about 20 to $30 \mathrm{~km}$ 